\section{ETHNOLOGICAL SOCIETY.}

WEDNESDAY, DEC. $21 \mathrm{sT}, 1859$.

Dr. HODGKIN IN THE CHAIR.

DR. STEPHEN H. WARD introduced to the notice of the members

TWO CRAIIA OF THE VEDDAH TRIBE IN CEYLON,

supposed, with the exception of one in the possession of $\mathrm{Mr}$. J. Barnard Davis, to be the only specimens in the country. They were procured by Mr. Bailey, of the Civil Service, and forwarded by Mr. Thwaites, of the Botanic Garden at Peradenia. One of the skulls, which was in a state of tolerably perfect preservation, was rather dolikho-cephalic, very narrow and keel-shaped, the extreme narrowness giving to the zygomatic arches an appearance of undue lateral projection. The jaws were somewhat prognathous, and the teeth in the sound state which is usual with savage tribes. In general capacity, the cranium was smaller than any one of several skulls, amongst them an Esquimaux, negro, \&c., which had been measured by Mr. Busk. It appeared to be that of a female, of from twenty-two to twenty-eight years of age. The lower, and a large portion of the upper, jaw of the second skull were wanting; but the cranium was broader and more capacious, the bones denser and heavier, and it appeared to be that of a male of about the middle period of life. The only detailed notices of these Veddahs are to be met with in the travels of Captain R. Knox, published about 200 years back, in the account of Ceylon by Dr. John Davy, and the recent work by Sir Emerson Tennent. These writers, and also Mr. Bailey and Mr. Bradford, from whom recent communications had been received, bear testimony to the fact that the Veddahs are the aborigines of the island, and that before the Christian era they retired before invaders from the banks of the Ganges to the jungles and hills in the south-east of Ceylon, where they have remained isolated for more than 2000 years. A custom which they have of never, if possible, coming into contact with other people, and of not showing themselves even when they engage in matters of barter with the travelling traders of the country, accounts for the maintenance of their isolation, and at the same time identifies them with the aboriginal inhabitants, as described by ancient writers. The Veddahs seen by Sir E. Tennent had flat noses, prognathous jaws, were of low stature, and very degraded in aspect. Mr. Bradford, however, speaks of one whom he met with as resembling very much a Cingalese coolie; and it may be remarked that they speak a dialect of the Cingalese language, though the more degraded are described as scarcely possessing an articulate tongue, and as communicating with one another by signals and guttural sounds. The Veddahs go about in nearly a nude state, their hair falling down to their miadle in matted lumps. They live in the forests, and at night seek shelter under rocks or in caves, or on platforms raised amid the trees. They depend for their subsistence on the bow and arrow, using their feet as well as hands in drawing the bow. In their diet they are omnivorous, but consider lizards and roasted monkey as the greatest delicacy. Sir E. Tennent says that they have no knowledge of a God or a future state; no temples, idols, prayers, or charms ; in short, that they exhibit no instinct even of religion. Their only ceremony is a sort of devil-dance, by which they avert evil. They do not bury their dead, but only cover them with leaves in the jungle. They have no idea of time or distance; no names for hours, days, or years; and, in the matter of education, are unable to count beyond five on their fingers. They have no amusements, and not even the rudest kind of music. The writer last quoted says further, that they are of gentle disposition, and though knowing nothing of virtue, rarely commit great crimes. They exhibit in a striking degree the effect of complete isolation, either in degrading man to, or keeping him in, a state of abject barbarism.

Dr. Krox made some interesting observations upon the skulls, and stated that in craniology he relied more upon general features than upon any system of measurement. $\mathrm{He}$ pointed out the full development of frontal sinuses which characterized both the specimens, and the fact that in the smaller of the two the ala of the sphenoid scarcely abutted upon the parietal bone.

Mr. Coll stated that the skulls were objects of much interest, and that he had made various unsuccessful efforts to procure one or two. He thought that we had not at present sufficient data for determining the affinities of these peculiar tribes.

After some remarks by the ChalkMas, a paper was read
"On the Races Inhabiting Cape Colony," by Thous as BuINes, Esq., which had been communicated by Dr. NorTo: SHAw. The notice of a modification of VON BAER's craniometer, by Mr. BusK, was deferred to another meeting.

\section{THE LONDON MEDICAL REGISTRATION ASSOCIATION.}

A MEETINe of the Vigilance Committee was held at the office, No. 5, Charing-cross, on Friday evening, December 30th, Dr. Wright in the chair. After some routine business, the question of the conduct of the Council of the Royal College of Surgeons of England in admitting Messrs. Horton and Meredith, of Dudley, as members of this College, came under consideration. In one of the letters received and read on this subject, as indicative of the indignation that pervades the profession, the following passage occurs:- "Is there no way of preventing such a shameful abuse of power in a corporate body - so antagonistic to the hard-earned boon which the long and persevering struggle of the medical reformers gained for us?" The feeling thus evinced was share $\vec{a}$ by those present, and a resolution was passed to the effect " that it should be recommended to the General Committee, at their next meeting, that a letter should be for warded by the President of the London Medical Registration Association to the President of the Medical Council, calling the attention of Sir B. C. Brodie to the course pursued by the Council of the College of Surgeons, reminding him of the provisions of clauses 20 and 21 of the new Medical Act, and pointing out the injury which would be inflicted by a continuance of such procedures on the part of the Council of the College of Surgeons."

Letters read from the Liverpool, Hereford, and Portsmouth Medical Registration Associations urged prosecutions against unqualified practitioners in certain localities named, and these communications were referred to proper quarters for determination as to ulterior proceedings in the cases brought under. notice. A letter from the Uxbridge Medical Book Club, proposing to join the Association, was also read and duly acknowledged. The steps already taken relative to the action intended to try the privileges of "surgeon-dentists" were reported on; and the Committee then adjourned until the next Friday evening, January 6 th.

\section{MANCHESTER MEDICAL REGISTRATION ASSOCIATION. \\ To the Editor of THE LANCET.}

Sir,-At a meeting of the Committee of the Manchester District Medical Registration Association, it was determined to seek the co-operation of other kindred Associations in the appointment of a deputation to wait upon the Home Secretary, the object being to express their great disappointment that the enforcement of penalties under the Medical Act has not as yet been undertaken by the Registrar or the Medical Council.

We shall be happy to correspond with any Association which may be favourable to the intended deputation, and in the meantime will feel obliged if you will give this a place in your columns,

We are, Sir, yours, \&c., H. M. Williamson,
J. Thorburi, Oxford-street, Manchester, Dec. $27 \mathrm{th}, 1859$.

YeLLOW FeVER at ST. Thomas's. - We regret to state that Mr. Morris, the surgeon of the Royal Mail Steam Company's ship La Plata, was seized with yellow fever, at St. Thomas's, on the 18th of December last, and fell a victim to this fatal malady five days afterwards. Mr. Morris had been some years in the service, and was deservedly held in the highest estimation by his brother officers. He was attended by a passenger, a regimental surgeon, in his last moments. In this instance it is a source of congratulation to state, that another medical officer was on board to treat the sick. Had the case been, as has occurred over and over again at these terrible yellow fever outbreaks, that no second medical officer could be found to attend the passengers and crew, the mortality might have been most fearful to relate. We trust that the attention of the directors of the company will be awakened to this serious omission in their duty towards the public. Dr. Finlay was the last gentleman whose name we recorded as having died of yellow fever. 